\title{
Narcotráfico na América do Sul: uma análise sobre violência nas redes da cadeia logística do tráfico de drogas na América do Sul (2010 - 2015)
}

\author{
Drug trafficking in South America: an analysis of \\ violence in the networks of the drug trafficking \\ logistics chain in South America (2010 - 2015)
}

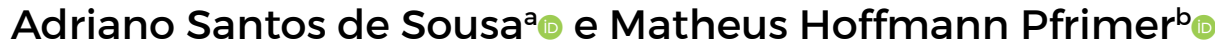

Resumo Os conflitos armados articulados à atividade do narcotráfico na América do Sul apresentam diferentes padrões espaciais. Essas configurações espaciais são dependentes da cadeia produtiva da cocaína e seus derivados que, por vezes, funcionam como fontes de financiamento das chamadas novas guerras. A relação entre recursos naturais e conflitos ainda foi pouco estudada no contexto sul-americano. Nesse sentido, o presente trabalho tem por objetivo descrever e analisar a configuração espacial dos narco-conflitos na América do Sul. Para isso, utilizamos o enfoque da economia política do conflito, acreditando que exista relação espacial entre espaços produtivos específicos da cadeia de produção e a letalidade e tipologia dos conflitos. Defende-se ainda que os espaços de distribuição e consumo de cocaína são especificamente aqueles que apresentam os maiores níveis de intensidade e letalidade de tais conflitos. No que se refere aos métodos, foram coletados dados quantitativos de apreensões de drogas (UNODC) e de homicídios por região (UCDP). A partir desses dados, construiu-se uma cartografia temática, através da qual analisamos as redes logísticas do narcotráfico na região.

Palavras-chave Narcotráfico. Conflitos. América do Sul. Cocaína.

Abstract Armed conflicts linked to the activity of drug trafficking in South America have different spatial patterns. These spatial configurations are dependent on the production chain of cocaine and its derivatives, which sometimes function as sources of financing for the so-called new wars. The relationship between natural resources and conflicts has still been little studied in the South American context, so this paper aims

a Mestrando no Programa de Pós-Graduação em Sociologia da Universidade Federal de Goiás (UFG), e-mail: adrianosou94@gmail.com

b Professor Adjunto de Relações Internacional da Faculdade de Ciências Sociais - UFG, pesquisador associado ao Núcleo de Estudos Globais/UFG, e-mail: matheuspfrimer@hotmail.com 
to describe and analyze the spatial configuration of narco-conflicts in South America. To this end, we use the perspective of the political economy of conflict, believing that there is a spatial relationship between specific productive spaces in the production chain and the lethality and typology of conflicts. Also, we argue that the spaces of distribution and consumption of cocaine are specifically those that present the highest levels of intensity and lethality of such conflicts. With regard to methods, quantitative data on drug seizures (UNODC) and the number of homicides by region (UCDP) were collected. Based on these data, a thematic cartography was constructed, in which we analyzed the logistical networks of drug trafficking in the region.

Keywords Trafficking. Conflicts. South America. Cocaine.

\section{INTRODUÇÃO}

O Brasil tem taxa de 30,5 homicídios a cada 100 mil habitantes - a segunda maior da América do Sul, depois da Venezuela, cuja taxa é de 56,8. No total, cerca de 1,2 milhões de pessoas perderam a vida por homicídios dolosos no Brasil entre 1991 e 2017 . Apesar de os estudos securitários abordarem a América do Sul como uma região livre de conflitos interestatais, o alto índice de homicídios demonstra que a região ainda apresenta elevada violência estrutural, cultural e física. Essas formas de violência se manifestam em diversos conflitos dentro dos Estados, e passam a ficar em evidência após o fim da Guerra Fria, encerrada em 1991. O protagonismo dos exércitos regulares cedeu espaço à participação de organizações criminosas como os cartéis de drogas, que ampliaram seu poder de letalidade e emprego da força. Mary Kaldor (1999, p. 5) denominou esse fenômeno como "Novas Guerras".

A apropriação da cadeia de produção, refino e distribuição está na base de sustentação de organizações criminosas como o Primeiro Comando da Capital (PCC), Comando Vermelho (CV), entre outras. Várias organizações ilícitas possuem diversos negócios em escala e têm adquirido uma capacidade de mercado para proporcionar produtos e serviços, determinando a vida cotidiana de determinadas áreas em cidades como Medellín, Lima, Rio de Janeiro, São Paulo, Caracas, Monterrey, Cidade do México e ainda algumas cidades da fronteira norte do México, como Juárez. Algumas dessas organizações se concentram no tráfico de drogas ilícitas e não raro combinam essas atividades com serviços.

1 Ver https://www.unodc.org/lpo-brazil/pt/frontpage/2019/o7/brasil-tem-segunda-maior-taxa-de-homicdios-da-amrica-do-sul--diz-relatrio-da-onu.html\#: :text=V\%C3\%ADdeos-,Brasil\%2otem\%20segunda\%2omaior\%2otaxa\%2ode\%2ohomic\%C3\%ADdios\%20da\%2O Am\%C3\%A9rica\%20do,Venezuela\%2C\%20com\%2056\%2C8. 
O uso dos derivados de folha de coca como recurso natural a fim de financiar atividades de organizações criminosas se dá pelo alto rendimento desse recurso quando refinado, bem como pelo monopólio da produção de coca na América do Sul. Acredita-se que 95\% da produção mundial de folhas de coca seja feita na região (Kopp, 2001: 15). Ademais,o tráfico de cocaína revela-se altamente lucrativo, pois seu valor por unidade de peso é elevado. Por fim, além de não envolver alta tecnologia, a produção não necessita de modais especiais para ser transportada (Fukumi, 2008, p. 55). Devido a facilidades logísticas e geográficas, a folha de coca se tornou o insumo mais rentável para produção de drogas na região, permitindo o financiamento de grupos armados.

O presente trabalho procura entender a relação entre a natureza dos espaços da cadeia logística do narcotráfico e o tipo de conflito que se desenvolve nestes espaços na América do Sul. Para tanto, realizamos a análise espacial da cadeia logística a partir de dados georreferenciados sobre conflitos armados coletados na Upsalla Conflict Data Base Program (UCDP), e coletamos dados de homicídios do Instituto Igarapé. Além disso, utilizamos dados de apreensões de drogas disponibilizados no United Nations Office on Drugs and Crime (UNODC).

Aqui cabe ressaltar alguns conceitos desses bancos de dados. Em primeiro lugar,o UCDP considera a existência de conflitos armados a partir do momento em que são registradas ocorrências que contabilizam 25 mortes ao longo de um ano durante o enfrentamento armado entre grupos. A instituição classifica os conflitos em três tipos: conflitos de base estatal (state based conflict), conflitos de base não-estatal (non state based conflict) e violência unilateral (one sided violence). Por fim, os dados do UNODC sobre a quantidade e tipo de derivados de folhas de coca apreendidos não possui uma tipologia específica; contudo, operacionalizamos quatro tipos de espaços diferentes: a) espaço da produção da matéria prima referindo-se ao local das plantações de coca; b) espaços responsáveis pelo tráfico internacional referindo-se aos locais onde apreende-se pasta base em corredores transfronteiriços; c) espaços de distribuição atacadista referindo-se aos locais de apreensão de Hidrocloreto de Cocaína; e, por fim d) espaços de comercialização varejista, caracterizados pela apreensão da Cocaína já misturada a outros insumos. A partir dessa escolha metodológica construímos uma cartografia temática. Os dados utilizados se referem ao período entre 2010 e 2015 - contexto no qual estudos reportam uma maior atividade transnacional de OCTs brasileiras, particularmente do Primeiro Comando da Capital (PCC). O recorte espacial se restringiu à América do Sul e os dados estão agregados por municipalidades, de forma que os resultados pudessem ser sensíveis na microescala. 
Organizamos o presente artigo a partir da articulação de três temas principais: a economia política da produção da cocaína; os fluxos transacionais do tráfico e a espacialidade e natureza dos conflitos armados na América do Sul. O primeiro tópico trata da economia da produção de coca e a maneira pela qual o crime organizado se apropriou da produção de folha de coca nos países andinos para criar uma rede narcotraficante. O segundo versa sobre as principais rotas de tráfico na América do Sul, observando os fluxos e métodos empregados para a distribuição dos derivados de coca. A terceira parte aborda a natureza e a espacialidade dos conflitos armados na região, mais particularmente aqueles financiados pela atividade do narcotráfico.

\section{A ECONOMIA POLÍTICA DA PRODUÇÃO DE COCAÍNA}

A crise econômica internacional de 1980 foi responsável por deixar os países andinos mais dependentes do cultivo de coca, principalmente dos narcodólares que se tornaram uma alternativa face à crise. O déficit na balança de pagamentos dos países da região favoreceu a chamada "cocalização da economia" (Boville, 2004, p. 64-81). Como resultado da crise econômica, as plantações se tornaram mais lucrativas do que qualquer outra cultura agrícola. No mesmo período, os chamados cartéis ampliaram sua forma de organização, conseguindo se adaptar às adversidades, e se estabeleceram como organizações criminosas transnacionais. As economias dos países produtores têm dependido da economia cocaleira em momentos de crise econômica, quando é comum a migração de trabalhadores urbanos para as plantações ilegais ou mesmo para o refino das folhas de coca (Fukumi, 2008, p. 14-5).

Os cartéis colombianos encontraram condições ideais para intensificar o crescimento do cultivo da folha de coca na Bolívia. A partir de então, passaram a organizar a produção demandando cada vez mais folhas de coca que, posteriormente, seriam processadas em pasta base de coca (Boville, 2004, p. 76). Um processo análogo também aconteceu com o Peru, que passou a fornecer a coca para os cartéis colombianos. Assim, de acordo com Boville (2004, p. 63), estabeleceu-se uma espécie de divisão de trabalho, com a diversificação entre locais que eram mais eficientes na produção, enquanto outros eram mais eficientes no refino.

A variedade, bem como a concentração de alcaloides na folha de coca da região de Huallaga, chamaram a atenção dos cartéis colombianos que, até então, eram abastecidos com coca boliviana. A promessa de reforma agrária e de melhores condições de vida atraíram milhares de pessoas para locais como San Martín, Vale Apurímac e Aguaytía, que depois encontraram no cultivo de coca uma alternativa 
de renda, ajudando a estabelecer essas regiões como produtoras da planta/erva (Boville, 2004, p. 70).

Em 2014, a produção de coca no Peru chegou a 62,5 mil hectares (Unodc, 2015, p. 11). Atualmente, as zonas de cultivo de coca legal naquele país estão distribuídas da seguinte maneira: Putumayo, Bajo Amazonas, Marañón, Alto Chicama, Alto Huallaga, Aguaytía, Palcazú - Pichis, Pachitea, El Vraem, La Convención y Lares, Kosñipata, San Gabán, Inambari, Tambopata (UNODC, 2015, p. 12).Dentre elas, ressalta-se que a zona com maior produção da folha de coca está em El Vraem, que é um acrônimo para Valle de los Rios Apurímac, Ene e Mantaro.

Na Bolívia, o cultivo de coca se concentra em duas regiões: Los Yungas de La Paz e Trópico de Cochabamba. O cultivo de folha de coca na Bolívia em 2014 foi realizado em 20,4 mil hectares (UNODC, 2015, p. 12) - Los Yungas de La Paz correspondeu a 70\% das áreas cultivadas, e Trópicos de Cochabamba, $30 \%$. Ressalta-se que a economia da folha de coca boliviana é responsável por parte significativa do PIB desse país. Em 2014, ela saltou de 0,9\% para 8,8\% do total da economia no setor agrícola (UNODC, 2015, p. 12). No mesmo ano, a produção da folha de coca legal rendeu em torno de 282 milhões de dólares.

A demanda por cocaína tem aumentado as áreas de cultivo de folha de coca nos países andinos nos últimos anos, fazendo a produção se ampliar nas áreas de cultivo legal e ilegal. Essa tendência tem variado no tempo e espaço. Embora o cultivo diminua em certos períodos em determinados países, observa-se que em curto espaço de tempo os indicadores da UNODC mostram o aumento do cultivo em outros países. Assim, a despeito dos esforços para erradicar plantações ilegais e apreender pasta base e outros derivados, a quantidade apreendida anualmente demonstra a ineficácia dessas ações.

Uma hipótese para esse fracasso são as múltiplas conexões das redes de narcotráfico. Com isso, se uma área de cultivo ilegal é destruída em Carrasco, Bolívia (UNODC, 2015, p. 13), ela pode não representar nada frente ao aumento da produção de coca em Nariño ou Putumayo, na Colômbia (UNODC, 2016, p. 85). Nesse sentido, observa-se que, apesar de o cultivo ter diminuído na Bolívia a partir de 2010 - saindo de 31 mil hectares para 20,4 mil hectares em 2014 (UNODC, 2015, p. 27) -, em um curto espaço de tempo as áreas cultivadas aumentaram na Colômbia, indo de 69 mil hectares em 2014 para 96 mil hectares em 2015 (UNODC, 2016, p. 85). De forma análoga, o cultivo também diminuiu no Peru a partir de 2012, quando a produção foi de 60,4 mil hectares para 42,9 mil hectares em 2014 (UNODC, 2015, p. 27). No entanto, ao analisar o cultivo dos países como um todo, verifica-se que a diminuição do cultivo em regiões específicas não afeta 
significativamente o crime transnacional, pois ele tem reorganizado sua capacidade produtiva aumentando o cultivo em outras localidades.

A capacidade de processamento de pasta base aumentou a partir de 2010, passando de $500 \mathrm{~kg}$ a 100okg por dia (UNODC, 2017, p. 74). Credita-se esse aumento às estruturas de processamento como o cristalizadero2, que tem sido encontrada em alguns laboratórios na Colômbia. Ademais, essa nova dinâmica de produção exige a adoção de outras estratégias para proteger o local do refino onde existem complexos de processamento.

O narcotráfico passou a realizar investimentos em infraestruturas em comunidades locais, oferecendo assistência sociale, em contrapartida, a comunidade começou a proteger esses locais (UNODC, 2017, p. 74). Ademais, o tráfico também passou a comprar a produção de folhas de coca de pequenos produtores locais a preços mais elevados, como forma de incentivar a produção (UNODC, 2017, p. 152). Assim, essa nova dinâmica mudou a forma de organização e operacionalização, com a criação de parcerias estratégicas entre proprietários de cultivo de folha de coca e proprietários de complexos de refino que, ao final, dividem os rendimentos na distribuição da droga (UNODC, 2017, p. 154).

A fase primária, da qual participam os produtores de folha de coca, não exerce nenhuma influência sobre o mercado de coca, tampouco é capaz de influenciar na definição dos preços. Dos 60\% dos produtores que vendem sua produção, apenas $40 \%$ conseguem realizar a extração e apenas $1 \%$ consegue chegar até a base de cocaína (UNODC, 2017, p. 78). Nesse sentido, de forma geral os produtores de folha de coca participam pouco do processo de extração e refino - etapa de maior valor agregado. Por fim, o lucro da cadeia de produção de cocaína fica praticamente todo com outros atores. Na fase secundária, o valor agregado dos derivados de coca pode ser de 16 a 39 vezes maior em relação ao preço comercializado no país de origem, sem considerar a adição de outras substâncias (UNODC, 2017, p. 78) já no final do processo logístico, quando o produto chega ao consumidor final.

A liderança do narcotráfico colombiano substituiu a máfia cubana, que antes tinha mais acesso aos Estados Unidos. A razão pela qual o tráfico colombiano conseguiu assumir o controle, de acordo com Filippone (1994, p. 325), é a posição geográfica da Colômbia, que não só está estrategicamente localizada entre os países produtores de coca como a Bolívia e o Peru, mas também possui saída para o mar.Assim, as condições espaciais favoreceram a atuação dos cartéis no que diz respeito à organização do espaço produtivo e logístico. Outros fatores também

2 Equipamento utilizado para processamento do cloridrato de cocaína. 
contribuíram para a ascensão dos cartéis colombianos, como os programas de erradicação de drogas no México em 1970. Eles aproveitaram esse momento para ampliar a sua atuação, criando seus próprios laboratórios. Os cartéis colombianos chegaram a representar $80 \%$ da cocaína apreendida mundialmente, e estima-se que os rendimentos dos cartéis chegaram a $\$ 20$ bilhões de dólares em 10 anos apenas com os mercados estadunidense e europeu (Filippone,1994, p. 323). Com esses rendimentos os cartéis passaram a se especializar, tornando-se uma rede organizacional multinacional.

Constituiu-se uma divisão transnacional do trabalho narcotraficante na América do Sul, na qual parte das plantações de folhas de coca se encontra na Bolívia, Peru e Colômbia. Enquanto no primeiro país o mercado consumidor de drogas é ínfimo, nos outros dois uma parte da produção é destinada ao mercado internacional, enquanto outra é comercializada no mercado nacional. A articulação entre esses países produtores e os mercados consumidores, regional e internacional ocorre por meio de rotas de distribuição. Os principais pontos de distribuição de drogas na região são a rota Caipira e a rota Amazônica. A primeira rota busca atender o mercado brasileiro, argentino e, mais recentemente, africano. Já a segunda destina-se ao transporte intercontinental de drogas à Europa e aos Estados Unidos. Dessa forma, a partir da natureza geográfica e do tipo de regulação do território, o tráfico de cocaína na América do Sul articula lugares com funções diferentes. Resta-nos compreender a natureza das articulações entre os pontos das redes sul-americanas do narcotráfico.

\section{DA ATUAÇÃO REGIONAL À TRANSNACIONALIZAÇÃO DO NARCOTRÁFICO: FLUXOS E MÉTODOS EMPREGADOS PARA A DISTRIBUIÇÃO DOS DERIVADOS DE COCA}

A transnacionalização do tráfico de drogas pode ser entendida como um processo que acompanhou a ascensão das políticas de abertura econômica no mundo, pois, com o objetivo de flexibilizar os processos burocráticos e aumentar a participação dos investimentos externos nas economias domésticas, criou-se também facilidades para o aumento das atividades ilegais.Para Adorno e Salla (2007), a emergência dessa forma de criminalidade não pode ser separada das condições e tendências que transformaram nossas sociedades desde os anos oitenta - com as mudanças e implementações de políticas neoliberais que acompanharam a globalização econômica e o enfraquecimento dos Estados nacionais. Nesse período, a maioria dos governos sul-americanos promoveu a desregulamentação dos mercados, em especial o mercado financeiro. Isso alterou as fronteiras 
nacionais, aumentando os fluxos de capital volátil; criou espaços de atividades ilícitas inéditas; e por fim, mas não menos importante, diminuiu os controles institucionais e a capacidade de combater o crime.

Sullivan e Bunker (2008, p. 40) afirmam que as mudanças na organização dos cartéis de drogas - desde a forma hierárquica organizacional à transformação em organização transnacional - conseguiram desafiar a legitimidade e soberania dos Estados. De acordo com eles, as evoluções dos cartéis passaram por três fases até se consolidarem como fenômeno desafiador para o Estado.

A primeira fase,na qual a atuação dos cartéis é descrita como Aggressive Competition, originou-se na Colômbia durante os anos 1980, impulsionada pelo consumo de cocaína dos EUA. A forma de organização desse tipo de cartel é conhecida como Medellín Model e se aproxima de uma economia de escala. De acordo com Sullivan e Bunker (2008:42), nessa primeira fase os cartéis assumiram uma postura violenta face ao Estado em razão de sua confrontação direta com as autoridades (Sullivan e Bunker, 2008, p. 43).

A segunda fase se desenvolveu com a ascensão do chamado Cartel de Cali. $\mathrm{O}$ grupo da cidade, que é até hoje uma das mais populosas da Colômbia, notabiliza-se mais pela corrupção do que pela violência. A forma de atuação dos cartéis nessa fase se tornou mais sofisticada, com os organizadores passando a optar pelo modelo de sub-co-opting, de modo a se aproximar das instituições estatais, destruindo sua legitimidade política e social (Sullivan e Bunker, 2008, p. 44).

A terceira fase dos cartéis, segundo Sullivan e Bunker (2008, p. 45-6), é uma consequência da concretização da cooptação e corrupção das instituições estatais. Os autores caracterizam esta fase como Criminal State Successor. Nesse contexto, os Estados passam a perceber os cartéis como forte ameaça a sua soberania. Assim, nesse momento, o Estado caminha para um tipo de narco-state ou criminal-state (Sullivan e Bunker, 2008, p. 45). Com efeito, aqui os cartéis já se encontram infiltrados na sociedade civil, tornando comum o uso da força para espalhar medo e intimidar a população.

De acordo com Soberón (2007, p. 272), os cartéis peruanos, colombianos e mexicanos que atuam na costa do pacífico utilizam dois modais de transporte: terrestre e fluvial, distribuídos nos eixos Ayacucho e Inca, Huallaga e Paita, Tingo Maria e El Callao. Em grande medida, a cocaína quem vem do Peru usa o modal fluvial do Trapézio Amazônico para adentrar o Brasil. Para isso, os rios Marañon e Ucayali são usados até a chegada em Manaus. Por outro lado, o modal terrestre é utilizado quando os derivados de coca seguem pelas fronteiras. Nesse caso, a droga sai pela fronteira de Águas Verdes Machala (Equador), divisa com Santa 
Rosa-La (Chile) e Desaguadero (Bolívia) (Soberón, 2007, p. 280), normalmente direção a Buenos Aires.

A distribuição e a comercialização dos derivados de coca se dá no varejo e atacado, sendo as fronteiras dos países as regiões onde se tem menor capilaridade e maior fluxo de compra e venda e, consequentemente, os locais mais propícios para desenvolvimento de atividades ilegais. As organizações criminosas se beneficiam das diferenças político-fiscais e mesmo jurídicas entre países para fazer lavagem de dinheiro. As várias transações bancárias são uma maneira de dificultar a busca pela origem do dinheiro. Os investimentos diretos e indiretos também são uma forma recorrente de lavagem de dinheiro, entrando na economia legal por meio da venda, associação e aquisição de empresas de fachada, por exemplo.

As redes de narcotráfico atuam frequentemente na territorialização $0^{3}$ dos espaços, utilizando-os estrategicamente tanto para operacionalizar os fluxos de cocaína no continente sul-americano, quanto para garantir que a mercadoria chegue até os consumidores finais fora do continente. Para territorializar, buscam conquistar espaços estratégicos que possuam características como a baixa densidade demográfica - como é o caso do norte do Brasil - e a dificuldade de acesso, seja pelo relevo ou mesmo pela floresta, como em várias partes das fronteiras brasileiras.

A inexistência de infraestrutura para modais terrestres que possam interligar o interior das cidades com as regiões portuárias demanda alternativas para a logística das redes de narcotráfico. Nesse sentido, o modal fluvial acaba funcionando como meio de transporte intermediário. Observa-se que este modal é frequentemente usado no norte do Brasil, onde os rios que passam pelos países produtores de coca são usados para o transporte de drogas. Assim, tem-se encontrado cada vez mais estruturas metálicas que mais se parecem com submarinos do que com embarcações propriamente ditas. Isso permite deduzir que as redes de narcotráfico têm se preocupado em sofisticar cada vez mais a sua maneira de utilizar os espaços disponíveis para realizar suas atividades de forma eficaz e inapreensível.

Alguns desses espaços se mostram importantes para a logística do narcotráfico. De acordo com Couto e Oliveira (2017), a Amazônia se configura como um espaço estratégico para as redes de narcotráfico que observam a região como espaço de possibilidades para expandir sua articulação. Nesse sentido, a região Amazônia funciona, de acordo com os autores, como uma "região-trânsito", que cumpre com

3 O conceito de territorialização é aquele discutido na Geografia Política, no qual se enfoca as disputas territoriais enquanto espaços de poder. 
o duplo papel de atender às demandas tanto internas quanto externas do comércio de cocaína (Couto e Oliveira, 2017).

O trabalho de Rebecca Steiman (1995) buscou, de forma descritiva, sintetizar os vários corredores de passagem de cocaína que ligavam os países da América do Sul, a maioria tendo com rota de destino o Brasil. Nesse esforço, observa-se o mapeamento das áreas de produção, as rotas de trânsito e os países de destino da droga dentro da América do Sul. Steiman (1995, p. 44) analisa a América do Sul sem, no entanto, preocupar-se em explicar as razões pelas quais essas rotas eram escolhidas pelo narcotráfico. $\mathrm{O}$ apontamento de que os corredores de tráfego estabelecidos entre os vários países teriam como direção final o Brasil pode levar, em certa medida, ao entendimento de que o país se configura como local de destino, quando na realidade se apresenta como um país de trânsito.

Sobre o transporte terrestre, observa-se que ele assume algumas especificidades. Nessa etapa a droga tende a seguir para as regiões portuárias, onde encontram-se as plataformas marítimas que fazem o escoamento do cloridrato de cocaína para destinos como os mercados estadunidense, europeu e africano. Até a chegada a essa fase, o modal fluvial pelo qual passam as drogas até a chegada ao Brasil, mencionado por Steiman (1995, p. 45), serve como subsidiário até o modal terrestre que, ao final, tem como destino as plataformas marítimas.

Nesse sentido, observa-se que as rotas e corredores de tráfico situados ao norte do Brasil são, na realidade, subsidiárias das rotas principais, uma vez que a necessidade logística das redes de narcotráfico são as plataformas marítimas. Essa é uma das razões pelas quais a rota caipira é uma das rotas principais e com maior fluxo de cocaína do Brasil.

\section{ESPACIALIDADE DOS CONFLITOS ARMADOS NA AMÉRICA DO SUL E O NARCOTRÁFICO}

Bagley (2013) aponta para questões que contribuíram para a contínua transformação do comércio de drogas e desenvolvimento dos grupos de organizações criminosas, tais como: o aumento da globalização do consumo de drogas; o limite da Guerra às Drogas liderada pelos Estados Unidos, especialmente nos Andes; a proliferação de áreas de cultivo e de rotas de contrabando na América do Sul; a dispersão e fragmentação do crime organizado em redes no nível regional, dentro dos países e fora deles; a falha de reforma política e desinstitucionalização; a falha da política de controle de drogas e crime estadunidense; a ineficiência das políticas de controle de drogas regional e internacional. 
Esses elementos implicaram uma nova espacialidade do narcotráfico, quase organizou a partir de redes nas quais a função desempenhada pelos pontos da logística se caracteriza a partir dos diferentes Estados na América do Sul. Cada ponto da rede realiza um papel na cadeia logística do tráfico. Nesse panorama, temos os Estados produtores de folhas de coca, como Colômbia, Equador, Bolívia e Peru; países de trânsito, como Paraguai, Uruguai e Venezuela; e os países como Brasil e Argentina, que além de terem a função de país de trânsito na rede logística do narcotráfico, também estão em vias de se consolidar como países de consumo. Cada ponto desta cadeia logística possui maior ou menor relação com a violência armada.

Levando em conta a construção das cartografias a partir dos dados coletados, podemos compreender melhor a relação espacial entre a natureza dos espaços do tráfico transnacional e a presença da violência armada. Levando em conta a tipologia dos espaços estabelecidas no início deste trabalho, analisaremos primeiro a relação dos espaços produtores da matéria prima. Grosso modo, os vales produtores de folhas de coca parecem não ter relação com os conflitos do tipo não-estatal, uma vez que podemos visualizar sua concentração apenas em dois Estados, dentre os quais apenas um se constitui como produtor. Os conflitos do tipo não-estatal, no caso colombiano, podem ser explicados pela competição entre cartéis rivais que buscam controlar espaços estratégicos para o tráfico.

A concentração de conflitos de base estatal próxima aos vales produtores de folhas de coca demonstra a existência de relações espaciais entre os vales produtores e os laboratórios de refino. Segundo Boville, (2004, p. 149), "a insistência em eliminar os fluxos de cocaína nos lugares de produção significa mover o conflito das guerrilhas dentro das zonas de produção e dos laboratórios de processamento".

Os aspectos históricos e políticos, tanto da Colômbia quanto do Peru, podem indicar o motivo dessa concentração de conflitos. Ambos os países sofreram forte pressão internacional para erradicar as plantações ilegais de coca e combater o narcotráfico. O Plano Colômbia e, consequentemente, a Guerras às Drogas, representa essa pressão internacional por uma resposta dos países andinos. Observa-se que esses Estados optaram por securitizar as questões envolvendo o narcotráfico, dando tratamento militar para o tema.

Em relação ao Brasil, a concentração de conflitos de base-não estatal no Rio de Janeiro na cartografia sugere a disputa entre facções do narcotráfico pelos espaços tidos como estratégicos. Nesse caso, podemos entender esses espaços como locais nos quais a presença do Estado se dá majoritariamente em um contexto de repressão policial. 


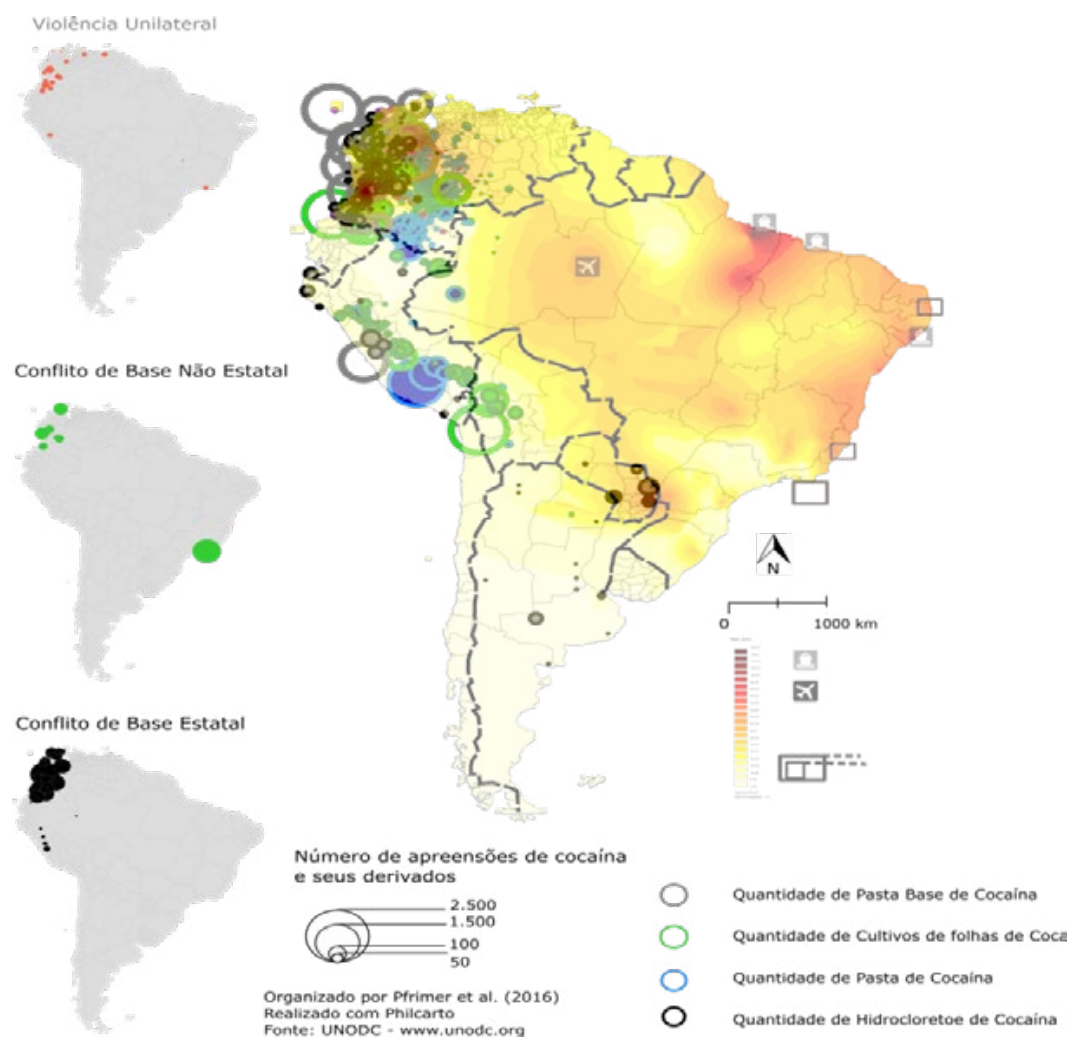

Mapa 1. Tipos de conflitos na América do Sul e apreensões de drogas. Fonte: Pfrimer et al (2016).

Observando mais atentamente a cartografia acima,percebe-se a concentração dos conflitos de Base Não Estatal e Conflitos de Base Estatal, bem como de Violência Unilateral, quando há a presença de hidrocloreto de coca. Assim, quanto maior o número de apreensões de hidrocloreto, maior a concentração desses eventos na cartografia. Ademais, a cartografia mostra que a tríplice fronteira de Paraguai, Argentina e Brasil se constituiu como um espaço de distribuição de drogas e, por conseguinte, de Conflito de Base não-estatal. Ressalta-se, ainda, que conforme (Sullivan e Bunker, 2008, p. 47) as redes de crime transnacional encontraram na tríplice fronteira o espaço ideal para desenvolvimento de suas atividades, pois nela os aspectos políticos e geográficos aproximam três países, cujo acesso nesse ponto é restringido pela floresta.

As atividades das redes de narcotráfico se organizam em três tipos logísticos de países: país-produtor, país de trânsito e país de consumo. Os países produtores são aqueles onde o cultivo de folha de coca ocorre e é permitido legalmente, embora possa haver restrições de áreas cultivadas. Os países de trânsito se caracterizam pelo alto número de apreensões de derivados de coca com destinação final a outros 
países. A destinação é na maioria das vezes para países fora da América do Sul, onde o preço do cloridrato de cocaína supera o do mercado interno sul-americano.

O Brasil deixou de ser apenas um país de trânsito na cadeia logística para assumir também a posição de país consumidor. Para territorializar os espaços, as redes narcotraficantes disputam entre si os espaços estratégicos, sobretudo aqueles que são espaços do comércio varejista. No varejo, os derivados de coca têm acrescido todos os custos da cadeia produtiva e logística ao produto final. As plataformas continentais, por sua vez, são usadas para venda de drogas no atacado. Nesses pontos não se observou nenhuma concentração de conflitos, independentemente da variedade do derivado de coca.

A concentração dos conflitos do tipo de base estatal tem maior incidência na Colômbia, demonstrando uma escolha política de enfrentamento ao tráfico na esteira de pressões externas. Como o principal produtor de coca da região e por abastecer os grandes mercados internacionais de cocaína, o país sofreu pressões internacionais para implementar uma política de guerra às drogas. Os conflitos de base estatal no caso colombiano representam a escolha política pela militarização das questões envolvendo drogas. Naquele país o narcotráfico deixou de fazer parte da agenda de segurança pública para figurar como ameaça ao Estado.

\section{CONCLUSÃO}

Voltando o nosso ponto de partida, buscamos entender a relação entre a natureza dos espaços da cadeia logística do narcotráfico e a violência armada. A partir da análise espacial empreendida pode-se afirmar que as configurações logísticas do narcotráfico engendram conflitos com características em comum. Em primeiro lugar, esses conflitos são majoritariamente do tipo de base estatal e não-estatal. Isso se expressa com a concentração desses tipos de conflito na Colômbia e Venezuela. A violência unilateral entre a sociedade civil e o Estado está presente em regiões nas quais existe uma demanda social grande. A exclusão social tem grande peso histórico para as populações daquelas regiões. Esses espaços configuram grandes centros urbanos e têm em comum a histórica marginalização da população mais pobre, que vive na periferia.

Segundo, a proximidade das apreensões de drogas do tipo pasta base próximo aos vales de produção de folhas de coca sugere também a proximidade dos laboratórios de refino de pasta base e a produção de folhas. A droga, nessa etapa, encontra-se ainda no processo logístico de transporte e em direção às plataformas continentais, onde toma destino transcontinental ou segue para pontos de venda no varejo da América do Sul. 
Por fim, o número de apreensões de produção de folhas de coca em áreas ilegais ao longo dos anos demonstra mais a capacidade do crime organizado em se reposicionar na cadeia de produção do que a política de erradicação de produção ilegal de folha de coca. Nesse sentido, observamos que a configuração dos espaços de produção, refino e consumo de cocaína tem se adaptado ao longo do tempo às mudanças do mercado consumidor.

\section{REFERÊNCIAS}

ADORNO, Sergio; SALLA, Fernando (2007). Criminalidade organizada nas prisões e os ataques do PCC. Estudos Avançados, v. 21, n. 61, p.7-29.

BAGLEY, Bruce (2013). The Evolution of drug trafficking organized crime in Latin America. Sociologia, Problemas e Práticas, v.70,p.99-123.

BUNKER, Robert J. e SULLIVAN, John P. Cartel (2010). Evolution revisited: third phase cartel potentials and alternative future in Mexico. Small Wars \& Insurgencies, v. 21, n. 1, p.30-54.

BOVILLE, Belén Luca de Tena (2004). The Cocaine War in Context Drugs. New York: Algora.

COUTO, Aiala Colares e OLIVEIRA, Isabela de Souza (2017). A geografia do narcotráfico na Amazônia. Geographia Opportuno Tempore, v. 3, n. 1, p. 52-64. http://www.uel. br/revistas/uel/index.php/Geographia/article/view/31774

FILIPPONE, Robert (1994). The Medellin Cartel: Why we can't win the drug war. Studies in Conflict \& Terrorism, v.17, n.4, p. 323-44.

FUKUMI, Sayaka (2010). Cocaine Trafficking in Latin America: EU and US Policy Responses. Drug and Alcohol Review, v. 29, n. 2, p. 229-30.

KALDOR, Mary (1999). New and Old Wars Organized Violence in Global Era. Stanford, CA: Stanford University Press.

KOPP, Pierre (2003). Political Economy of Illegal Drugs, v.1. New York: Routledge.

PFRIMER, M. H.; BARBOSA JÚNIOR, Ricardo César; LEAL, Juliana Brito Santana;BARBOSA,Wilton Dias; FRANÇA,Juliana Hungria;FERREIRA JÚNIOR, Fernando Jorge Saraiva (2016). Recursos naturais e conflitos armados na América do Sul: invertendo o nexo causal dos estudos securitários. Anais do XIII Congresso Acadêmico sobre Defesa Nacional. https://www.gov.br/ defesa/pt-br/arquivos/ensino_e_pesquisa/defesa_academia/cadn/artigos/ XIII_cadn/recursosa_naturaisa_ea_conflitosa_armadosa_naa_americaa_doa_ sula_invertendoa_oa_nexoa_causala_dosa_estudosa_securitarios.pdf

STEIMAN, R. (1995). O mapa da droga. Monografia. Rio de Janeiro: Universidade Federal do Rio de Janeiro, Instituto de Geociências, Departamento de Geografia. 
UNODC- United Nations Office on Drugs and Crime (2016). Estado Plurinacional de Bolivia: Monitoreo de Cultivos de Coca 2016. https://www.unodc.org/documents/ crop-monitoring/Bolivia/2016_Bolivia_Informe_Monitoreo_Coca.pdf (acesso em: 9 jun. 2019).

UNODC- United Nations Office on Drugs and Crime (2017). Monitoreo de territórios afectados por cultivos ilícitos 2017. https://www.unodc.org/documents/ crop-monitoring/Colombia/Colombia_Monitoreo_territorios_afectados_cultivos_ ilicitos_2017_Resumen.pdf (acesso em: 9 jun. 2019). 